Check for updates

Cite this: RSC Adv., 2018, 8, 11388

Received 20th January 2018

Accepted 13th March 2018

DOI: $10.1039 / c 8 r a 00580 j$

rsc.li/rsc-advances

\section{Improving frictional properties of DLC films by surface energy manipulation}

\begin{abstract}
Jia Wang, (D) ${ }^{a}$ Kan Zhang, ${ }^{\text {a }}$ Fuguo Wang ${ }^{\star b}$ and Weitao Zheng (D)*a
Surface energy is essential to the friction properties of materials, but until now the investigating scope for DLC films has still been narrow. In this paper, we try to expand the surface energy scope of DLC films to their limits by surface modification and study their influence on friction properties. In this case, we not only control the surface energy of DLC films but also manipulate that of the counter balls, by using piranha etching and octadecyltrichlorosilane (OTS) modification. The surface compositions, wettabilities and friction properties of DLC films and counter balls were investigated. The results indicate that the surface energies of DLC films and counter balls can be adjusted successfully in the ranges of 31.2 to $73.73 \mathrm{~mJ} \mathrm{~m}^{-2}$ and 15.69 to $72.93 \mathrm{~mJ} \mathrm{~m}^{-2}$, respectively. The frictional tests show that all the as-modified DLC films retain relatively stable friction curves, which derive from their good load-carrying and wearresistance capabilities. Specifically, the DLC-OH covered with vast oxygen-containing groups shows poor frictional properties, owing to its high surface energy and strong adhesion. In contrast, the DLC-OTS exhibits amazing friction reduction properties, due to its ultra-low surface energy and special film structure.
\end{abstract}

\section{Introduction}

Diamond-like carbon (DLC) films provide unique properties, such as high hardness, low friction, wear resistance, optical transparency, good biocompatibility, and so on, ${ }^{1-3}$ which make them interesting to both academic research and industrial applications..$^{4-6}$ However, as we know, the typical DLC films, which are composed primarily of carbon and hydrogen or incorporate certain small amounts of foreign elements, commonly possess a moderate surface energy around 36 to 48 $\mathrm{mJ} \mathrm{m}^{-2} .7,8$ Even through the DLC films were applied to some micro frictions or particular fields, the influence of moderate surface energy on the tribological property of DLC film is very limited. But in practice, a large amount of engineering devices and materials are of great difference in surface properties (hydrophobic or hydrophilic). To meet the requirements of specific operating environment, surface modification with hydrophilic or hydrophobic organic molecules or groups is a feasible strategy. ${ }^{9-11}$ That is to say, besides outstanding mechanical and antiwear properties that other materials do not own, surface modification could give DLC films more options or possibilities in terms of surface wettabilities. ${ }^{12-15}$ For instance, Choi et al. ${ }^{16}$ demonstrated that, compared with pure DLC films, the heptadecafluoro-1,1,2,2-tetradecyltriethoxysilane modified

\footnotetext{
${ }^{a}$ State Key Laboratory of Superhard Materials, Department of Materials Science, Key Laboratory of Automobile Materials, MOE, Jilin University, Changchun 130012, P. R. China. E-mail:WTZheng@jlu.edu.cn

${ }^{b}$ State Key Laboratory of Solid Lubrication, Lanzhou Institute of Chemical Physics, Chinese Academy of Sciences, Lanzhou 730000, P. R. China. E-mail: fgwang@licp. cas.cn
}

DLC films showed better frictional characteristics, which is attributed to the hydrophobic nature of the surfaces. Coincidentally, an experiment of Ma et al. ${ }^{17}$ also confirmed this point of view and showed that the modified DLC films with hydrophobicities exhibited good reducing-friction and load-carrying capabilities. In addition, in most cases the monocrystal silicon is fabricated as small-scale systems, but due to its lowhardness and the surface force, the performances and operating lifetimes of all these Si-based small-scale systems decrease. $^{18,19}$ In contrast, DLC films with excellent hydrophobicities can be applied precisely as substrates for future molecular devices and electrochemical applications, such as MEMS. ${ }^{20-23}$ Apparently, the resulting benefits are ultra-low adhesion, friction and wear. As a matter of fact, hydrophobicity is not the only hot topic in surface properties, and sometimes hydrophilicity is also desired. In the water environment, DLC films with preeminent hydrophilicities are capable of absorbing water molecules to develop a water film on them, thus a good boundary lubrication layer forms between the friction pairs and it can prevent the pairs from severe wear. ${ }^{24}$ Furthermore, DLC films have admirable biocompatibilities, which combined with the hydrophilicities, can also be employed in some kinds of biomedical devices. Conceivably, various kinds of cells could be adhered and grown on these surfaces successfully. As Hopper $e t a{ }^{25}$ recently reported that, by using a UV functionalization method, DLC films were modified to introduce surface-bound amine and aldehyde groups, the modification process made the DLC films more hydrophilic and dramatically promoted the adhesion of neurons and increased the viability of neurons seeded to the 
surfaces. Besides, Biswas et al. ${ }^{\mathbf{2 6}}$ found the hydrophilic DLC films also could be ideal substrates for protein immobilization. It is clear that the surface properties of modified DLC films that influence the physical or chemical interactions between contacts can govern their surface performances directly and even generate some particular functionalities, as discussed above. Therefore, the ability to regulate or switch the surface properties of DLC films is evidently quite attractive for many applications in small-scale systems, biomedical devices and so on. This is why the intelligent control of material's surface properties has been an everlasting topic. So, in this study, we hope to modify the DLC films by a simple method coupled with optimized design strategy, expand the difference of surface property as great as possible to adapt to all kinds of specific operating environments. Generally speaking, the surface property discrepancy of each surface between the contacts dominates the tribological behaviour of friction pairs. Herein, we divide the as-modified DLC films into four frictional groups deliberately (from hydrophilic/hydrophilic to hydrophobic/ hydrophobic). According to the different interfacial friction phenomena, the relative frictional mechanisms are also explained in detail that contributes to update the advanced modification techniques timely and accelerate the production of modified DLC films for a wide range of applications.

\section{Experimental}

\subsection{Materials}

Octadecyltrichlorosilane (OTS, 97\%) was purchased from Shanghai Boer Chemical Reagent Co., Ltd. Hydrogen peroxide $\left(\mathrm{H}_{2} \mathrm{O}_{2}, 30 \%\right.$, Xilong Chemical Co., Ltd.), sulfuric acid $\left(\mathrm{H}_{2} \mathrm{SO}_{4}\right.$, 98\%, Baiyin Liangyou Chemical Reagent Co., Ltd.), toluene (99.5\%, Rionlon Bohua Pharmaceutical \& Chemical Co., Ltd.), ethanol (99.7\%, Rionlon Bohua Pharmaceutical \& Chemical Co., Ltd.), and diiodomethane $\left(\mathrm{CH}_{2} \mathrm{I}_{2}, 98 \%\right.$, Tianjin Institute of Chemical Reagent), were all used as received. Ultrapure water $(18.2 \mathrm{M} \Omega \mathrm{cm})$ used throughout the experiment was purified by using a Milli-Q system from Millipore Co.

\subsection{Preparation of DLC film}

DLC films were deposited on $\mathrm{Si}$ (100) wafers by dc pulse-PECVD technique, using a mixture of $\mathrm{CH}_{4}$ plus $\mathrm{Ar}$ and $\mathrm{H}_{2}$ as the feedstock. Prior to deposition, the substrates were ultrasonically cleaned in acetone and ethanol for $20 \mathrm{~min}$, respectively. Then the substrates were treated with Ar plasma sputtering at a bias voltage of $-800 \mathrm{~V}$ for $30 \mathrm{~min}$ so as to remove the native oxides on the Si surfaces. Subsequently, the deposition of DLC films were carried out at the bias voltage of $-800 \mathrm{~V}$ and the high frequency $(80 \mathrm{kHz})$ for $4 \mathrm{~h}\left(10 \mathrm{sccm} \mathrm{CH}_{4}, 20 \mathrm{sccm} \mathrm{H}_{2}\right.$, and $100 \mathrm{sccm}$ Ar).

\subsection{Surface modification}

The typical hydrophilic surfaces were produced by piranha treatments (a mixture of $\mathrm{H}_{2} \mathrm{SO}_{4}$ and $\mathrm{H}_{2} \mathrm{O}_{2}$ ). In detail, the precleaned DLC substrates were immersed into piranha solution $\left(\mathrm{H}_{2} \mathrm{O}_{2}: \mathrm{H}_{2} \mathrm{SO}_{4}=4: 7\right)$ at $90{ }^{\circ} \mathrm{C}$ for $1 \mathrm{~h}$. After that, the modified samples were rinsed with ultrapure water and then dried in $\mathrm{N}_{2}$ stream. The resulting samples were defined as DLC-OH. By further modifying the DLC-OH substrates, it is easy to obtain the hydrophobic surfaces. The DLC-OH substrates were immersed into $1 \mathrm{mmol} \mathrm{L}^{-1}$ OTS toluene solution at room temperature for $2 \mathrm{~h}$. Related modification process could be expressed as a chemical reaction equation (eqn (1), ' $R$ ' is the DLC-OH surface). After that, the modified samples were rinsed with ethanol and then dried in $\mathrm{N}_{2}$ stream. And these asfabricated samples were defined as DLC-OTS.

$$
\mathrm{CH}_{3}\left(\mathrm{CH}_{2}\right)_{17} \mathrm{SiCl}_{3}+3 \mathrm{H}-\mathrm{O}-\mathrm{R}=\mathrm{CH}_{3}\left(\mathrm{CH}_{2}\right)_{17} \mathrm{Si}(-\mathrm{O}-\mathrm{R})_{3}+3 \mathrm{HCl}
$$

The schematic view of whole modification process was shown in Fig. 1. The $\mathrm{Al}_{2} \mathrm{O}_{3}$ balls (diameter of $5 \mathrm{~mm}$ and Rockwell hardness of 80) were experienced a same treatment process as DLC films as described above, the resulted hydrophilic and hydrophobic surfaces were defined as $\mathrm{Al}_{2} \mathrm{O}_{3}-\mathrm{OH}$ and $\mathrm{Al}_{2} \mathrm{O}_{3}$-OTS, respectively.

\subsection{Characterization}

The measurement of X-ray photoelectron spectroscopy (XPS) was carried out on a Perkin-Elmer PHI-5702 system, using Al Ka radiation to investigate the chemical compositions and bonding states of the as-fabricated films. The pass energies are $29.35 \mathrm{eV}$ and the binding energies were referenced to the C1s line at $284.8 \mathrm{eV}$ from adventitious carbon. The stationary water

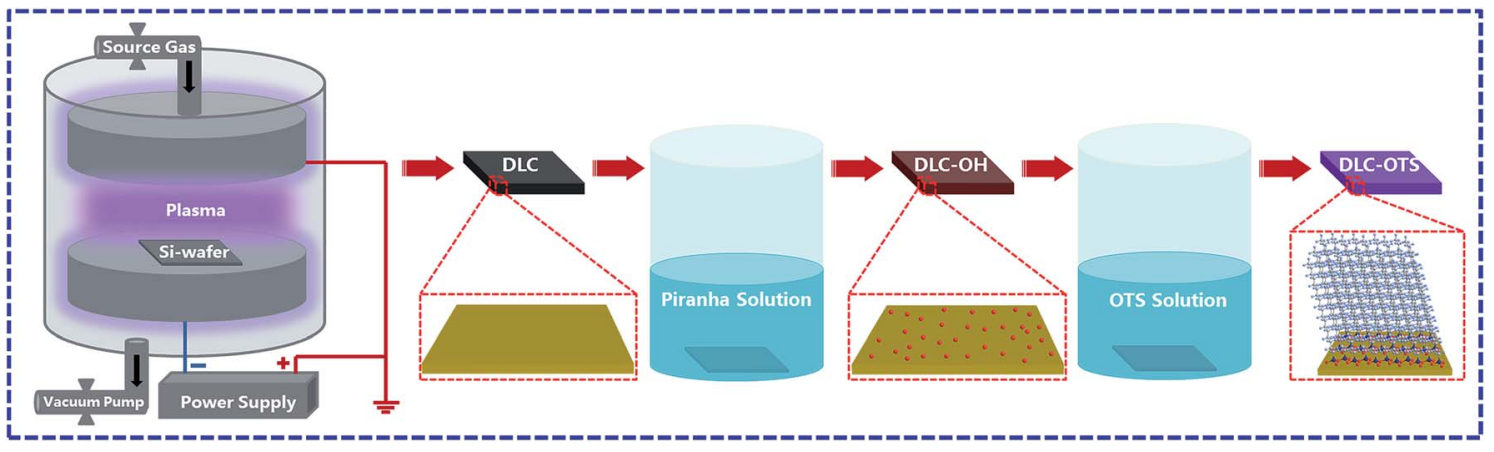

Fig. 1 Schematic view of surface modification of DLC films. 
contact angles of samples was examined using an optical contact angle meter (DSA100, Krüss, Germany) at ambient temperature $\left(25{ }^{\circ} \mathrm{C}\right)$, four replicate measurements were taken for each specimen and the contact angles were determined automatically by using the Laplace-Young fitting algorithm, the contact angles of $\mathrm{Al}_{2} \mathrm{O}_{3}-\mathrm{OH}$ and $\mathrm{Al}_{2} \mathrm{O}_{3}$-OTS samples were all examined using $\mathrm{Al}_{2} \mathrm{O}_{3}$ flat surfaces which contain the same compositions as the $\mathrm{Al}_{2} \mathrm{O}_{3}$ balls.

\subsection{Friction test}

The friction tests $(0.2 \mathrm{~N}, 1 \mathrm{~Hz}$, and $5 \mathrm{~mm})$ were performed by using the ball-on-flat testing geometry in a commercially available reciprocating sliding device (UMT-3). The friction properties of four friction pairs (DLC-OH/ $/ \mathrm{Al}_{2} \mathrm{O}_{3}-\mathrm{OH}$, DLC-OH/ $/ \mathrm{Al}_{2} \mathrm{O}_{3}-\mathrm{OTS}$, DLC-OTS $/ \mathrm{Al}_{2} \mathrm{O}_{3}-\mathrm{OH}$, and DLC-OTS/ $/ \mathrm{Al}_{2} \mathrm{O}_{3}$-OTS) were examined all in ambient environment, while the relative humidity and room temperature were approximately $20 \%$ and $19{ }^{\circ} \mathrm{C}$, respectively.

\section{Results and discussion}

\subsection{XPS}

Two as-fabricated films which denominated as DLC-OH and DLC-OTS have been successfully prepared, via a simple two-step process. The great chemical composition changes of two surfaces were testified by X-ray photoelectron spectroscopy, as shown in Fig. 2. In order to distinguish their changes more clearly, the XPS result of pure DLC is also displayed. Fig. 2a is the XPS survey spectra of three samples, which all mainly composed of carbon and oxygen. In fact, the DLC belongs to the typical hydrocarbon film, and its O1s signal results mostly from adventitious oxygenous contamination which adhered to the DLC film and eliminated easily in piranha solution. As a comparison, the stronger signal of O1s is detected in DLC-OH, which indicates the appearance of oxygen containing groups during piranha etching. Moreover, successful preparing of DLCOTS is verified by the weakness of O1s signal and the presence of $\mathrm{Si} 2 \mathrm{p}$ and Si2s signals. Fig. $2 \mathrm{~b}$ shows the $\mathrm{C}$ and $\mathrm{O}$ atomic\% of three samples. Obviously, DLC-OH has the lowest content of $\mathrm{C}$ $(85.23 \%)$ and the highest content of $\mathrm{O}(14.77 \%)$, because the surface is covered by a vast number of oxygen containing groups. On the contrary, DLC-OTS has the highest content of C $(89.92 \%)$ and the lowest content of $\mathrm{O}(10.08 \%)$, which is primarily attributed to the long-chain organic molecules of OTS covered on the modified surface. The spectra of C1s, which gives further insight into the composition and structure, are shown in Fig. 2c. It is found that the C1s peaks of DLC and DLC-OH all can be fitted into three components around 284.8, 286.4, and $289.1 \mathrm{eV}$, and usually assigned to $\mathrm{C}-\mathrm{C}, \mathrm{C}-\mathrm{O}$, and $\mathrm{C}=\mathrm{O}$ bonds, respectively. The sources of these bonds have been discussed above. Differently, only one peak (the $\mathrm{C}-\mathrm{C}$ bond) is observed in DLC-OTS, it further demonstrates that the modified surface is completely covered with the long hydrocarbon chain molecules of OTS. In addition, Fig. 3 also exhibits the XPS results of $\mathrm{Al}_{2} \mathrm{O}_{3}$ balls with different modifications. Except the peaks of C1s and O1s, the peaks of $\mathrm{Al} 2 \mathrm{~s}$ and $\mathrm{Al} 2 \mathrm{p}$ can also be observed in Fig. 3a, which come absolutely from the $\mathrm{Al}_{2} \mathrm{O}_{3}$ balls themselves. But with the modifying of $\mathrm{Al}_{2} \mathrm{O}_{3}$ ball step by step, the Al signals weaken piece by piece. As seen in the survey spectrum of $\mathrm{Al}_{2} \mathrm{O}_{3}$ OTS, the Al signals tend to disappear nearly, besides, the O1s signal weakens to the minimum and the C1s signal enhances to the maximum. Meanwhile, the content variations of $\mathrm{C}, \mathrm{O}$, and $\mathrm{Al}$ of three simples are concluded in Fig. 3b. After piranha etching the $\mathrm{Al}_{2} \mathrm{O}_{3}$ ball, the $\mathrm{Al}_{2} \mathrm{O}_{3}-\mathrm{OH}$ is obtained, the contents of $\mathrm{C}$ and $\mathrm{Al}$ all decrease and the content of $\mathrm{O}$ increases, due to the formation of lots of oxygen containing groups on the $\mathrm{Al}_{2} \mathrm{O}_{3}$ ball. When dealing with the $\mathrm{Al}_{2} \mathrm{O}_{3}-\mathrm{OH}$ by OTS further, the $\mathrm{Al}_{2} \mathrm{O}_{3}$-OTS is obtained, the contents of $\mathrm{O}$ and $\mathrm{Al}$ all decrease to the minimum (17.06\% and $8.2 \%$ ) and the content of $\mathrm{C}$ increases to the maximum $(74.73 \%)$, it attributes to the long hydrocarbon chain molecules cover the $\mathrm{Al}_{2} \mathrm{O}_{3}$ ball intactly.

\subsection{Contact angle}

Water contact angle measurements testify directly that the surface modification of DLC films is successful. As shown in
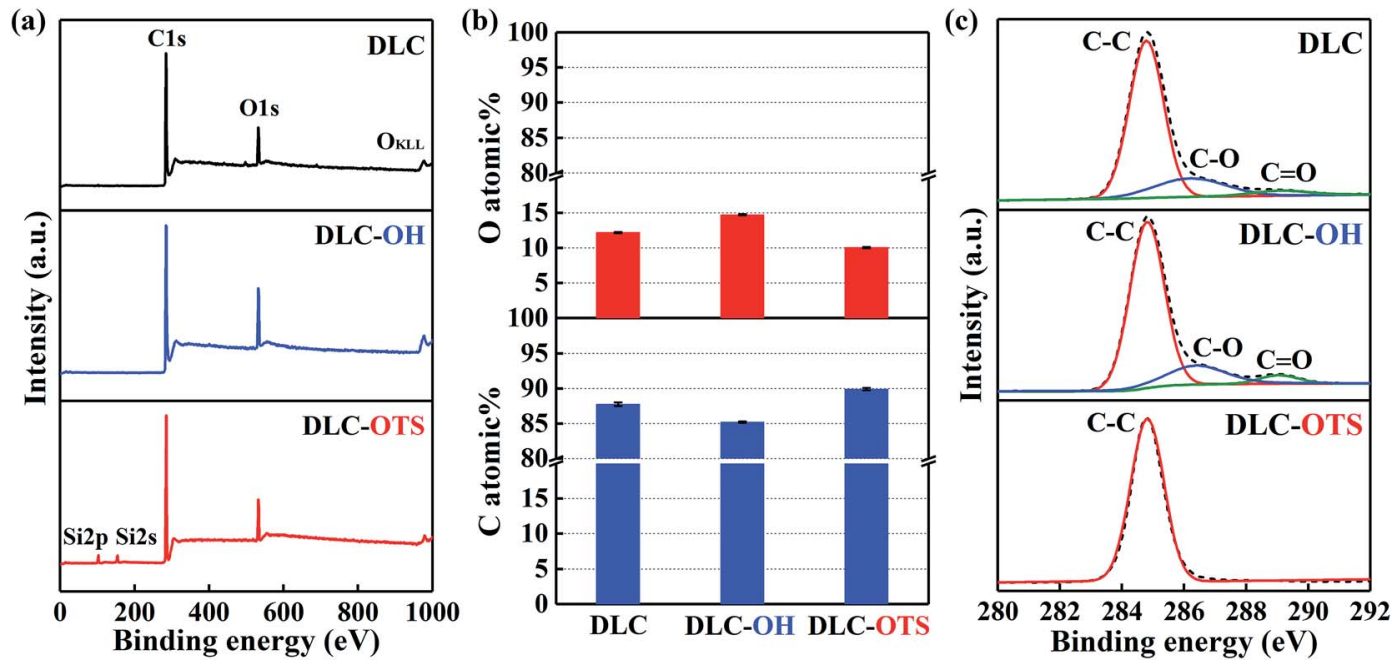

Fig. 2 XPS characterization of DLC films with different modifications: survey spectra (a); C and O atomic\% (b); and C1s spectra (c). 

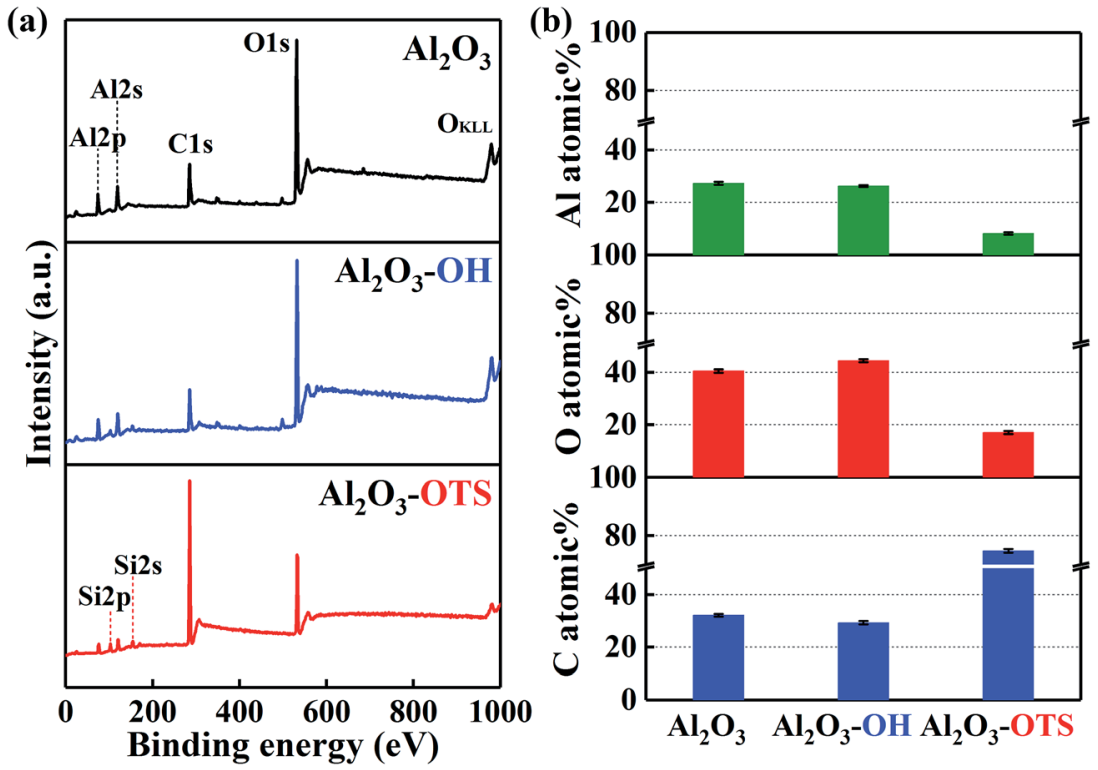

Fig. 3 XPS characterization of $\mathrm{Al}_{2} \mathrm{O}_{3}$ balls with different modifications: survey spectra (a); $\mathrm{C}, \mathrm{O}$, and $\mathrm{Al}$ atomic\% (b).

Fig. 4a, the change from hydrophilic to hydrophobic is recognizable at a glance. Similarly, the pure DLC film is just used as a reference substance here. It is clear in Fig. $4 \mathrm{~b}$ that the contact angle of pure DLC usually is about $66.6^{\circ}$. While the DLC-OH shows an amazing hydrophilic property (as small as $3.3^{\circ}$ ) mainly due to the formation of a mass of oxygen containing groups (such as hydroxyl, carbonyl, and epoxy groups) on the surface. As an opposite simple, the DLC-OTS exhibits an outstanding hydrophobic property (as large as $115.3^{\circ}$ ) which origins from the numerous long hydrocarbon chain molecules on its surface. Thus it can be seen that, via a simple two-step process, the controllable modify of DLC can be achieved successfully. In addition, by using the contact angle measure of two solutions with big polarity different and the OWRK (OwensWendt-Rabel-Kaelble) method (eqn (2)), ${ }^{8,27}$ the surface energies and their components of as-modified simples can be calculated easily. In order to ensure the accuracy of results, the deionized water with strong polarity and $\mathrm{CH}_{2} \mathrm{I}_{2}$ reagent with low polarity are selected.

$$
\gamma_{\mathrm{L}}(1+\cos \theta) / 2=\sqrt{\gamma_{\mathrm{S}}^{\mathrm{D}} \gamma_{\mathrm{L}}^{\mathrm{D}}}+\sqrt{\gamma_{\mathrm{S}}^{\mathrm{P}} \gamma_{\mathrm{L}}^{\mathrm{P}}}
$$

$\theta$ contact angle $\left(^{\circ}\right) ; \gamma_{\mathrm{L}}$ total surface tension of solution $\left(\mathrm{mN} \mathrm{m}^{-1}\right),\left(\gamma_{\mathrm{L}}=\gamma_{\mathrm{L}}^{\mathrm{D}}+\gamma_{\mathrm{L}}^{\mathrm{P}}\right) ; \gamma_{\mathrm{L}}^{\mathrm{D}}$ dispersive component of surface tension $\left(\mathrm{mN} \mathrm{m}^{-1}\right) ; \gamma_{\mathrm{L}}^{\mathrm{P}}$ polar component of surface tension $\left(\mathrm{mN} \mathrm{m}^{-1}\right) ; \gamma_{\mathrm{S}}$ total surface energy of sample $\left(\mathrm{mJ} \mathrm{m}^{-2}\right),\left(\gamma_{\mathrm{S}}=\gamma_{\mathrm{S}}^{\mathrm{D}}+\right.$ $\left.\gamma_{\mathrm{S}}^{\mathrm{P}}\right) ; \gamma_{\mathrm{S}}^{\mathrm{D}}$ dispersive component of surface energy $\left(\mathrm{mJ} \mathrm{m}^{-2}\right)$;
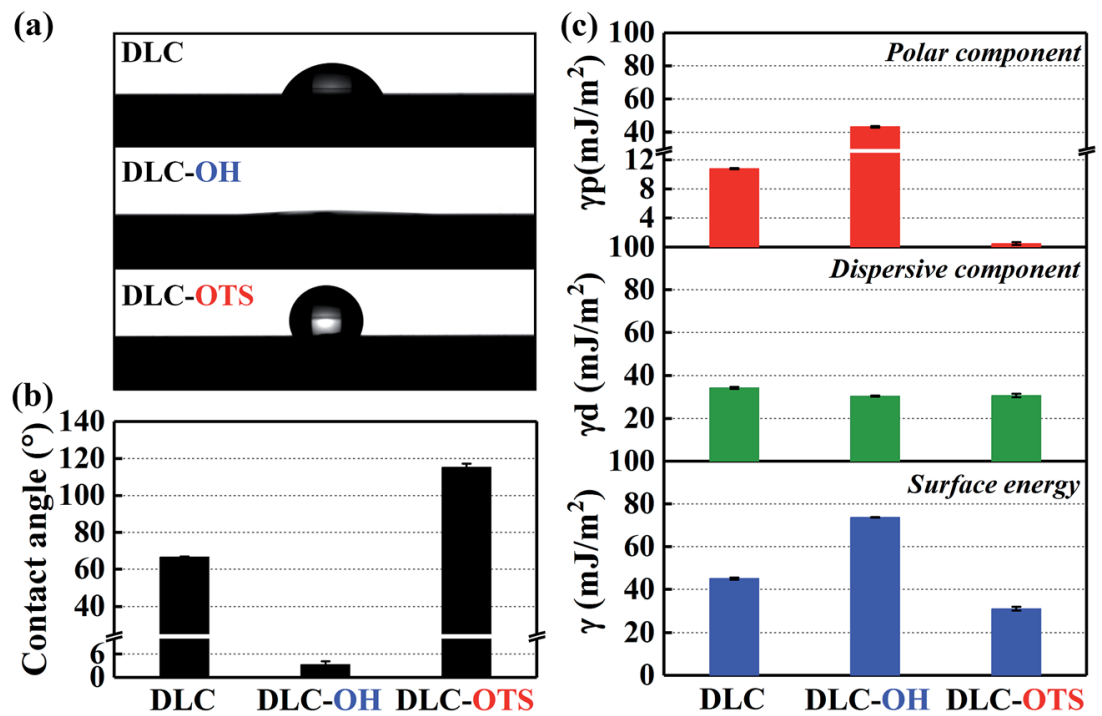

Fig. 4 Digital images of water drop profiles and static water contact angles of DLC films with different modifications (a) and (b); surface energies and their components of DLC films with different modifications (c). 
$\gamma_{\mathrm{S}}^{\mathrm{P}}$ polar component of surface energy $\left(\mathrm{mJ} \mathrm{m} \mathrm{m}^{-2}\right) ; \mathrm{H}_{2} \mathrm{O} \gamma_{\mathrm{L}}^{\mathrm{D}} \approx$ $21.8 \mathrm{mN} \mathrm{m}^{-1}, \gamma_{\mathrm{L}}^{\mathrm{P}} \approx 51 \mathrm{mN} \mathrm{m}^{-1} ; \mathrm{CH}_{2} \mathrm{I}_{2} \gamma_{\mathrm{L}}^{\mathrm{D}} \approx 49.5 \mathrm{mN} \mathrm{m}^{-1}, \gamma_{\mathrm{L}}^{\mathrm{P}} \approx$ $1.3 \mathrm{mN} \mathrm{m}^{-1}$.

Apparently, as summarized in Fig. 4c, the DLC-OH has the highest surface energy $\left(73.73 \mathrm{~mJ} \mathrm{~m}^{-2}\right)$ and the DLC-OTS has the lowest $\left(31.2 \mathrm{~mJ} \mathrm{~m}^{-2}\right)$, as a comparison, the surface energy of pure DLC is about $45.16 \mathrm{~mJ} \mathrm{~m}^{-2}$. A further finding is that, actually the really reason which affects the surface energies having so tremendous differences is the polar component. The polar component of DLC-OH reaches its maximum $\left(43.22 \mathrm{~mJ} \mathrm{~m}^{-2}\right)$, far greater than that of DLC-OTS $\left(0.49 \mathrm{~mJ} \mathrm{~m}^{-2}\right)$. By contrast, the dispersive components of three simples have no significant difference, all ranging from 30 to $34 \mathrm{~mJ} \mathrm{~m}^{-2}$. For experimental purpose, the same measurement of as-modified $\mathrm{Al}_{2} \mathrm{O}_{3}$ balls is also concluded in Fig. 5. Indubitability, the results of $\mathrm{Al}_{2} \mathrm{O}_{3}$ balls coincide with that of the DLC simples. It can be seen in Fig. $5 \mathrm{a}$ and $\mathrm{b}$, the contact angle of $\mathrm{Al}_{2} \mathrm{O}_{3}-\mathrm{OH}$ is as low as $4.2^{\circ}$ and that of the $\mathrm{Al}_{2} \mathrm{O}_{3}$-OTS is as high as $135.4^{\circ}$. By further numerical calculation, the surface energies and their components of as-modified $\mathrm{Al}_{2} \mathrm{O}_{3}$ balls are obtained, the surface energy of $\mathrm{Al}_{2} \mathrm{O}_{3}-\mathrm{OH}$ is about $72.93 \mathrm{~mJ} \mathrm{~m}^{-2}$ and that of the $\mathrm{Al}_{2} \mathrm{O}_{3}$ OTS is only $15.69 \mathrm{~mJ} \mathrm{~m}^{-2}$.

\subsection{Friction test}

By the simple two-step modifying process, two as-fabricated films with opposite wetting properties are prepared. Friction experiment is the most direct way of investigating the influence of surface modifications on their friction performances. In order to enlarge the differences of friction pairs, in Fig. 6, the asmodified simples are divided into four groups: DLC-OH/ $/ \mathrm{Al}_{2} \mathrm{O}_{3}$ $\mathrm{OH}$, DLC-OH $/ \mathrm{Al}_{2} \mathrm{O}_{3}$-OTS, DLC-OTS $/ \mathrm{Al}_{2} \mathrm{O}_{3}-\mathrm{OH}$, and DLC-OTS/ $\mathrm{Al}_{2} \mathrm{O}_{3}$-OTS, respectively. Because the surfaces of DLC-OH and $\mathrm{Al}_{2} \mathrm{O}_{3}-\mathrm{OH}$ are stacked with a mass of oxygen containing groups, the form of $-\mathrm{OH}$ used in the schematic view as shown in Fig. $6 \mathrm{a}$ does not mean there are no other functional groups, such as carbonyl and epoxy groups. Similarly, the form of $-\mathrm{CH}_{3}$ is also used due to the numerous long hydrocarbon chain molecules which covered on the surfaces of DLC-OTS and $\mathrm{Al}_{2} \mathrm{O}_{3}$-OTS. The dynamic friction curves of four groups which reflect the real friction phenomenons directly are displayed in Fig. 6b. From an overall perspective, the four friction curves remain relatively stable and do not produce distinct fluctuations during the entire friction measurement period with $1800 \mathrm{~s}$, which derives from the good load-carrying and wear-resistance capabilities of as-modified DLC films and the robust binding capacity between DLC films and functional monolayer. Combined with Fig. 6c, we can observe that, the friction pairs of DLC-OH/ $/ \mathrm{Al}_{2} \mathrm{O}_{3}-\mathrm{OH}$ have the highest friction coefficient about 0.375. This is because the pairs with vast polar groups (hydroxyl, carbonyl, and epoxy groups) generally possess higher surface energy and a relatively strong interaction during the sliding, which could result in a higher adhesion and need to dissipate more energy, therefore lead to a higher friction force. Meanwhile, in ambient environment, the presence of water molecules has a negative effect on friction coefficient, ${ }^{28}$ because the polarized pairs are quite hydrophilic and the interfacial nano-scale adhesion aroused by capillary force is significant. A number of water nanobridges are formed by capillary condensation between the polarized pairs, which can promote capillary shear interactions besides the solid-solid contact friction..$^{29,30}$ It is expected that, if the polarized pairs are applied in extremely humid or water environment, the hydrophilic pairs are easy to attract plenty of water molecules to adsorb, it will be easier to form a good water lubrication layer to reduce friction. As an opposite comparison, the friction pairs of DLC-OTS/ $\mathrm{Al}_{2} \mathrm{O}_{3}$-OTS exhibit an amazing friction reduction property with the value as lower as 0.081 . As described in Fig. 6a, the terminal groups of OTS $\left(-\mathrm{CH}_{3}\right)$ serve to passivate the surfaces of DLC film and $\mathrm{Al}_{2} \mathrm{O}_{3}$ and prevent adhesive interaction with dangling bonds on the counter faces, and the forms of $-\mathrm{CH}_{3} /-\mathrm{CH}_{3}$ also raise the interface repulsion.
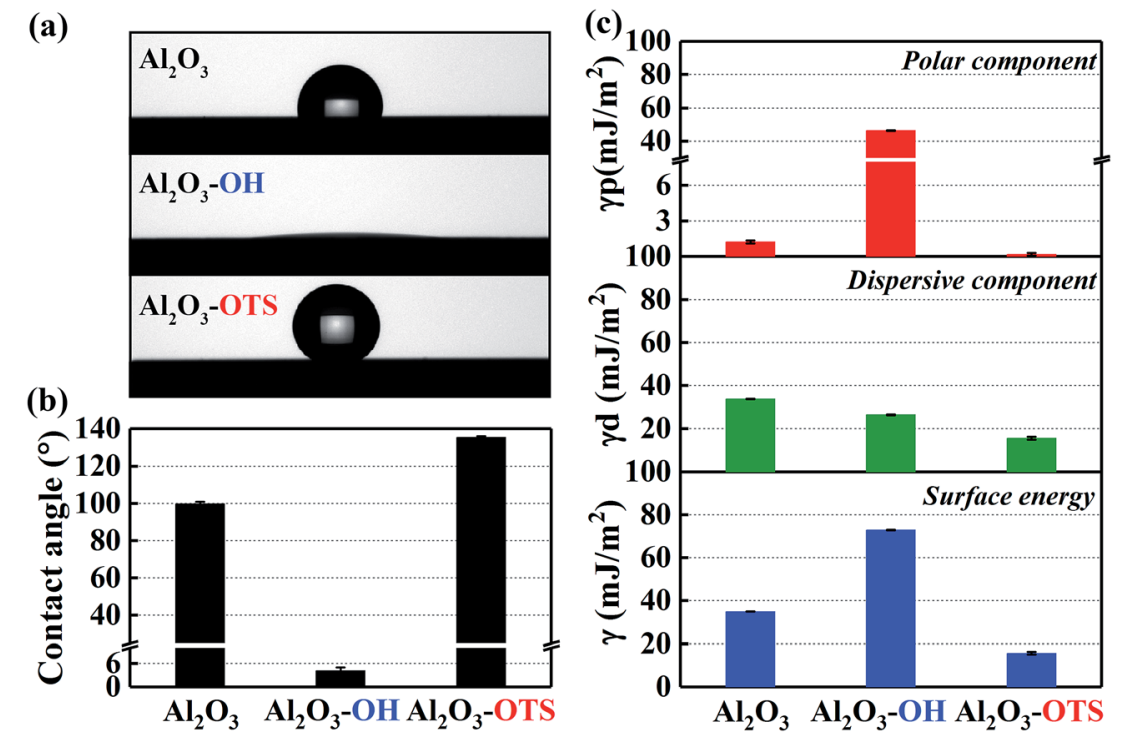

Fig. 5 Digital images of water drop profiles and static water contact angles of $\mathrm{Al}_{2} \mathrm{O}_{3}$ balls with different modifications (a) and (b); surface energies and their components of $\mathrm{Al}_{2} \mathrm{O}_{3}$ balls with different modifications (c). 
(a)

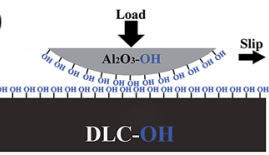

(b)
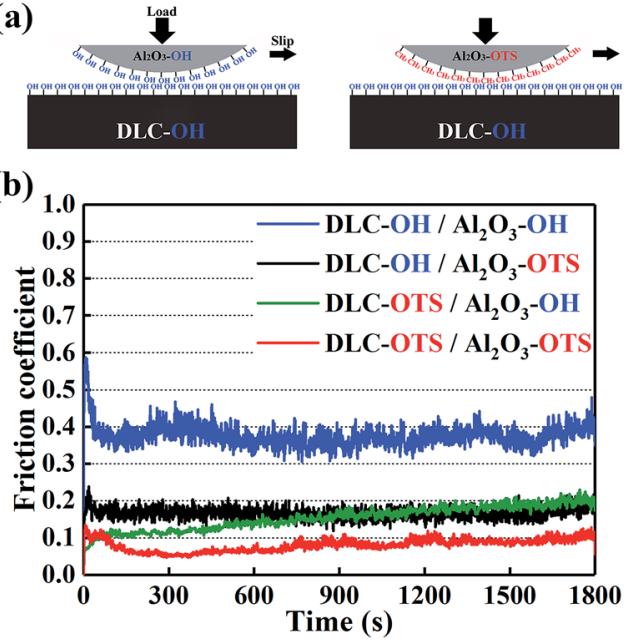
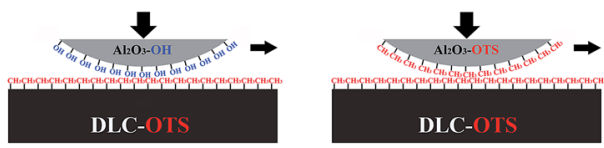

(c)

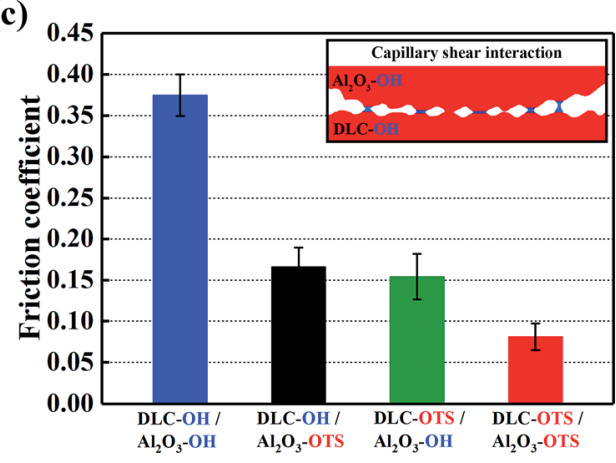

Fig. 6 Schematic view of frictional test with four friction pairs (a); dynamic friction curves (b); mean friction coefficient of four pairs and the inset shows the schematic of capillary force (c).

Ultimately, the ultra-low surface energies of DLC-OTS and $\mathrm{Al}_{2} \mathrm{O}_{3}$-OTS play a key role in reducing the interfacial friction. Furthermore, the dense long hydrocarbon chain molecules (octadecyl) concentrated on both surfaces constitute a nonpolar monolayer with remarkable flexibility, elasticity, and loadcarrying capacity, and the special low-energy alkane-like structures further promote the decrease of friction coefficient. As for the friction pairs of DLC-OH/ $/ \mathrm{Al}_{2} \mathrm{O}_{3}$-OTS and DLC-OTS $/ \mathrm{Al}_{2} \mathrm{O}_{3}$ $\mathrm{OH}$, the friction coefficients are very close, but it is still relatively low compared with DLC-OH/ $/ \mathrm{Al}_{2} \mathrm{O}_{3}-\mathrm{OH}$, which is attributed to the friction reduction property of OTS. Based on the discussion above, it can be suggested that the hydrophilic combinations of $-\mathrm{OH} /-\mathrm{OH}$ are appropriate for boundary lubrication or extremely humid environment, such as biomedical devices. On the contrary, the hydrophobic combinations of -OTS/-OTS are more suitable for the molecular devices and electrochemical applications, such as MEMS.

\section{Conclusion}

DLC films were modified by using a simple two-step strategy to extend their discrepancy of surface property. The DLC-OH was produced only by piranha etching and the DLC-OTS was acquired through subsequent surface modification of the DLC$\mathrm{OH}$ with OTS. The DLC-OH has the highest surface energy $\left(73.73 \mathrm{~mJ} \mathrm{~m}^{-2}\right)$ and outstanding hydrophilic property with a water contact angle as small as $3.3^{\circ}$, while the DLC-OTS has the lowest surface energy $\left(31.2 \mathrm{~mJ} \mathrm{~m}^{-2}\right)$ and excellent hydrophobic property with a water contact angle as large as $115.3^{\circ}$. By the same method, $\mathrm{Al}_{2} \mathrm{O}_{3}-\mathrm{OH}$ and $\mathrm{Al}_{2} \mathrm{O}_{3}$-OTS also obtained. Four frictional groups were designed deliberately and the frictional test result demonstrated that all the groups remain relatively stable friction curves, which derives from the good loadcarrying and wear-resistance capabilities of as-modified DLC films. The pairs of DLC-OH $/ \mathrm{Al}_{2} \mathrm{O}_{3}-\mathrm{OH}$ showed a poor frictional property (friction coefficient: 0.375 ) because the pairs with vast polar groups generally possess higher surface energy and a relatively strong interaction during the sliding. In contrast, the pairs of DLC-OTS $/ \mathrm{Al}_{2} \mathrm{O}_{3}$-OTS exhibit an amazing friction reduction property with the value as lower as 0.081 , due to their ultra-low surface energies and special film structures. It is evident that, by a simple modifying process, we can easily regulate the surface properties of DLC films as great as possible and expand their application range in almost all kinds of specific operating environments, such as from small-scale systems to biomedical devices.

\section{Conflicts of interest}

There are no conflicts to declare.

\section{Acknowledgements}

This work was supported by National Natural Science Foundation of China (Grant No. 51602122), National Key Research and Development Program of China (2016YFA0200400), Program for JLU Science and Technology Innovative Research Team (2017TD-09), Innovation Foundation of the 46th Research Institute of China Electronics Technology Group Corporation Program (Grant No. CJ20160902), and the China postdoctoral Science Foundation (Grant No. 2016M600229, 2017T100207).

\section{References}

1 A. Erdemir, Tribol. Int., 2004, 37, 1005-1012.

2 C. A. Charitidis, Int. J. Refract. Met. Hard Mater., 2010, 28, 5170.

3 F. Piazza, D. Grambole, D. Schneider, C. Casiraghi, A. C. Ferrari and J. Robertson, Diamond Relat. Mater., 2005, 14, 994-999.

4 R. Cruz, J. Rao, T. Rose, K. Lawson and J. R. Nicholls, Diamond Relat. Mater., 2006, 15, 2055-2060.

5 M. K. Fung, K. H. Lai, C. Y. Chan, I. Bello, C. S. Lee, S. T. Lee, D. S. Mao and X. Wang, Thin Solid Films, 2000, 368, 198-202. 
6 R. Hauert, Diamond Relat. Mater., 2003, 12, 583-589.

7 M. Kalin and M. Polajnar, Tribol. Int., 2013, 66, 225-233.

8 M. Kalin and M. Polajnar, Appl. Surf. Sci., 2014, 293, 97-108.

9 Y. Liu, X. Fu, Y. Bu, J. Zhang, J. Zhang and L. Wu, Surf. Coat. Technol., 2012, 208, 51-56.

10 M. Tan, H. Zhang, Y. Wang, H. Ma, J. Zhu and J. Han, Appl. Surf. Sci., 2008, 254, 6332-6336.

11 Y. Wang, L. Wang, S. Wang, R. J. K. Wood and Q. Xue, Surf. Coat. Technol., 2012, 206, 2258-2264.

12 J. Deval, T. A. Umali, E. H. Lan, B. Dunn and C.-M. Ho, J. Micromech. Microeng., 2004, 14, 91-95.

13 T. Kato, M. Kawaguchi, M. M. Sajjad and J. Choi, Wear, 2004, 257, 909-915.

14 C. Corbella, S. Portal-Marco, M. Rubio-Roy, E. Bertran, G. Oncins, M. A. Vallvé, J. Ignés-Mullol and J. L. Andújar, J. Phys. D: Appl. Phys., 2011, 44, 395301.

15 J. C. Love, L. A. Estroff, J. K. Kriebel, R. G. Nuzzo and G. M. Whitesides, Chem. Rev., 2005, 105, 1103-1169.

16 J. Choi, T. Ishida, T. Kato and S. Fujisawa, Tribol. Int., 2003, 36, 285-290.

17 M. Bai, Y. F. Mo and J. Q. Ma, Proc. Inst. Mech. Eng., Part J, 2009, 223, 705-714.

18 H. W. Liu, S. I. U. Ahmed and M. Scherge, Thin Solid Films, 2001, 381, 135-142.

19 S. Y. Song, S. L. Ren, J. Q. Wang, S. R. Yang and J. Y. Zhang, Langmuir, 2006, 22, 6010-6015.
20 A. A. Ogwu, T. I. T. Okpalugo and J. A. D. McLaughlin, AIP $A d v .$, 2012, 2, 032128.

21 R. A. Singh, K. Na, J. W. Yi, K.-R. Lee and E.-S. Yoon, Appl. Surf. Sci., 2011, 257, 3153-3157.

22 S. A. Smallwood, K. C. Eapen, S. T. Patton and J. S. Zabinski, Wear, 2006, 260, 1179-1189.

23 D. C. Pham, K. Na, S. Piao, I. J. Cho, K. Y. Jhang and E. S. Yoon, Nanotechnology, 2011, 22, 395303.

24 Q. Wei, X. Pei, J. Hao, M. Cai, F. Zhou and W. Liu, Adv. Mater. Interfaces, 2014, 1, 1-8.

25 A. P. Hopper, J. M. Dugan, A. A. Gill, E. M. Regan, J. W. Haycock, S. Kelly, P. W. May and F. Claeyssens, Mater. Sci. Eng., C, 2016, 58, 1199-1206.

26 H. S. Biswas, J. Datta, D. P. Chowdhury, A. V. Reddy, U. C. Ghosh, A. K. Srivastava and N. R. Ray, Langmuir, 2010, 26, 17413-17418.

27 R. Simič, M. Kalin, J. Kovač and G. Jakša, Appl. Surf. Sci., 2016, 363, 466-476.

28 A. Alazizi, A. J. Barthel, N. D. Surdyka, J. Luo and S. H. Kim, Friction, 2015, 3, 85-114.

29 E. Riedo, F. Levy and H. Brune, Phys. Rev. Lett., 2002, 88, 185505.

30 M. Lee, B. Kim, J. Kim and W. Jhe, Nat. Commun., 2015, 6, 7359. 